\title{
Peran Aspek Kelembagaan Subak dalam Konteks Pengendalian Alih Fungsi Lahan \\ (Kasus Subak Semat, Desa Tibubeneng, Kecamatan Kuta Utara, Kabupaten Badung)
}

\author{
NI LUH MADE KUSUMA PARAMITA DEWI, I DEWA PUTU OKA SUARDI, \\ I DEWA GEDE RAKA SARJANA
}

\author{
Jl. PB. Sudirman Denpasar 80233 \\ E-mail: nlmkparamita@ymail.com \\ okasuardi@yahoo.com
}

Program Studi Agribisnis, Fakultas Pertanian, Universitas Udayana

\begin{abstract}
TheRole of Institutional Aspects of Subak in the Context of Land Conversion Control (A Case at Subak Semat, Village of Tibubeneng, Sub-District of Kuta Utara,Regency of Badung)
\end{abstract}

Land conversion phenomenon that occurred in Bali is very high. The great number of land conversion leads to reduced agricultural land in an irrigation system of Subak. It will affect the sustainability of Subak. Subak role in the institutional aspects must be considered in controlling land conversion. The purpose of this study was to determine how the roles of the institutional aspects of water control system in the context of land conversion control at Subak Semat, Sub-District of Kuta Utara. The scope of this research is the institutional role ofSubak as controller of the land conversion. The study examined three indicators, namely regulation, Subak activities, services and facilitation of Subak. The research method was a qualitative descriptive method.Based on the research results, judging from the three indicators of research, namely regulation, Subak activities and services and facilitation, institutional role in regulation needs to accommodate the provisions of the ban on land conversion into traditional rules of awig awig. The role of the institutional aspects of the activities, services and facilitation has been at a good category, each categories was good with a score $70 \%$ and $80 \%$. The provisions of the ban on land conversion into traditional rules of awig awigSubak is needed with a score $81,17 \%$ so that the land conversion can be controlled. The lack of clear boundaries related to the ban on land conversion will be the reference for the members of Subak if they want to sell their land. In addition, the role of activities, services and facilitation of Subak still need to be improved to be in much better category.

Keywords: land, conversion, institutional, control 


\section{Pendahuluan}

\subsection{Latar Belakang}

Alih fungsi lahan merupakan perubahan spesifik yang dimana lahan yang dulunya difungsikan sebagai lahan untuk bercocok tanam berangsur-angsur berubah menjadi lahan dengan multifungsi pemanfaatan. Alihfungsi lahan yang tidak terkendali bisa berdampak pada kapasitas penyediaan pangan dan bahkan jika terjadi dalam jangka pajang akan menciptakan kerugian sosial (Iqbal dan Sumaryanto, 2007).

Subak tidak hanya terbatas pada organisasi pengelolaan air dan jaringan irigasi, namun berkaitan erat pada produksi pangan, ekosistem lahan sawah beririgasi, ritual keagamaan yang terkait dengan budidaya padi. Oleh karena itu, subak dinyatakan memiliki banyak manfaat (multi-functional benefits) (Sutawan, 2008).

Subak sebagai suatu lembaga memiliki beberapa aspek didalamnya. Terdapat beberapa jenis kelembagaan yang terkait dibidang pertanian, seperti lembaga petani yang berada pada kawasan lokalitas (local institution), yang berupa organisasi keanggotaan (membership organization) atau kerjasama (cooperatives), yaitu petanipetani yang tergabung dalam kelompok kerjasama (Uphoff, 1986 dalam Sandy Cahyono, 2010). Kelembagaan yang terdapat dalam subak belum bisa menjalankan perannya dengan baik, sehingga terjadi alih fungsi lahan yang sangat tinggi. Tidak maksimalnya peranan yang dilakukan oleh kelembagaan dalam subak dapat mengancam keberlangsungan subak. Berdasarkan uraian tersebut, maka menarik untuk dikaji peranan kelembagaan dalam subak sebagai pengendali alih fungsi lahan pada Subak Semat.

\subsection{Rumusan Masalah}

Rumusan masalah pada penelitian ini adalah bagaimana peran aspek kelembagaan subak dalam konteks pengendalian alih fungsi lahan pada Subak Semat, Desa Tibubeneng, Kecamatan Kuta Utara, Kabupaten Badung?

\subsection{Tujuan Penelitian}

Mengetahui bagaimana peran aspek kelembagaan subak dalam konteks pengendalian alih fungsi lahan pada Subak Semat, Desa Tibubeneng, Kecamatan Kuta Utara, Kabupaten Badung.

\section{Metode Penelitian}

\subsection{Lokasi dan Waktu Penelitian}

Lokasi penelitian dilaksanakan di Subak Semat, Desa Tibubeneng, Kecamatan Kuta Utara, Kabupaten Badung. Pertimbangan pemilihan lokasi penelitian adalah karena Subak Semat merupakan subak yang paling banyak mengalami alih fungsi lahan pada Kecamatan Kuta Utara (BPP, 2014). Penelitian ini dilaksanakan dari bulan Januari s.d. Juli 2016. 


\subsection{Populasi, Responden, dan Informan Kunci}

Populasi merupakan keseluruhan subjek penelitian (Arikunto 2002:208) Populasi dalam penelitian ini adalah seluruh anggota aktif pada Subak Semat yang berjumlah 130 orang. Responden pada penelitian ini meliputi seluruh anggota subak yang berstatus sebagai pemilik lahan yang berjumlah 34 orang. Seluruh responden diambil dari seluruh anggota yang berstatus pemilik lahan. Informan kunci merupakan tokoh yang dianggap mampu memberikan informasi lebih rinci mengenai data penelitian. Adapun informan kunci pada penelitian ini adalah pekaseh dan sekretaris Subak Semat.

\subsection{Jenis dan Sumber Data}

Jenis data dalam penelitian ini adalah data kualitatif dan data kuantitatif. Sumber data terdiri atas data primer dan data sekunder. Data primer merupakan data yang diperoleh dari melakukan survei lapangan dengan menggunakan semua metode data original, sedangkan data sekunder merupakan data yang sebelumnya telah dikumpulkan oleh lembaga tertentu dan dipublikasikan kepada masyarakat pengguna data (Kuncoro, 2003). Data primer bersumber dari responden penelitian, yaitu seluruh anggota Subak Semat yang berstatus sebagai pemilik dan penggarap lahan. Data sekunder diperoleh dari melihat teori-teori yang ada dengan membaca literatur, dan juga bisa melihat dari catatan atau berkas administrasi yang dimiliki oleh pengurus Subak Semat.

\subsection{Variabel dan Pengukuran}

Variabel digunakan untuk mengetahui bagaimana peranan kelembagaan dalam subak sebagai pengendali alih fungsi lahan pada Subak Semat. Peran kelembagaan dalam subak sebagai pengendali alih fungsi lahan akan diketahui dengan melihat tiga indikator, yaitu regulasi mengatur larangan alih fungsi lahan, aktivitas subak, dan pelayanan dan fasilitasi subak. Semua indikator akan diukur dengan pemberian skor.

\subsection{Analisis Data}

Data yang terkumpul pada penelitian ini akan dianalisis dengan menggunakan metode analisis deskriptif kualitatif. Data yang diperoleh dari hasil penelitian berupa data kualitatif dan juga kuantitatif yang akan disajikan dalam bentuk narasi dan tabel yang disusun secara sistematis dan efisien. Analisis dibantu dengan menggunakan metode skoring dalam mengukur setiap variabel penelitian. Skor minimum adalah 1 dan skor 5 merupakan skor maksimum. Berdasarkan interval kelas yang didapatkan, maka kategori peran aspek kelembagaan subak dalam konteks pengendalian alih fungsi lahan pada Subak Semat dirumuskan pada Tabel 1. 
Tabel 1.

Kategori Peran Aspek Kelembagaan Subak dalam Konteks Pengendalian Alih Fungsi Lahan pada Subak Semat

\begin{tabular}{ccc}
\hline Skor & $\begin{array}{c}\text { Presentase Pencapaian } \\
\text { Skor }\end{array}$ & $\begin{array}{c}\text { Kategori Peran Aspek Kelembagaan Subak } \\
\text { dalam Konteks PengendalianAlih Fungsi } \\
\text { Lahan }\end{array}$ \\
\hline 1 & $20-36$ & Sangat Buruk \\
2 & $>36-52$ & Buruk \\
3 & $>52-68$ & Sedang \\
4 & $>68-84$ & Baik \\
5 & $>84-100$ & Sangat Baik \\
\hline
\end{tabular}

\section{Hasil dan Pembahasan}

\subsection{Regulasi pengendalian alih fungsi lahan}

Subak memiliki peraturan yang lebih dikenal dengan awig-awig. Peraturan terbaru yang telah didtetapkan bahwa subak wajib memiliki aturan yang tertulis. Peraturan tersebut dibuat melalui pelaksanaan rapat subak. Peraturan tersebut akan ditetapkan jika telah mendapat persetujuan dari seluruh anggota subak. Hal tersebut akan dibahas ketika rapat subak, yang biasanya dilakukan secara rutin. Peraturan yang ditetapkan pada suatu subak harus menyesuaikan dengan kebutuhan dari masing-masing subak. Keberadaan peraturan yang sesuai dengan kebutuhan dari masing-masing subak akan memberikan pengaruh yang baik bagi jalannya suatu lembaga.

Tidak terdapat aturan atau ketentuan-ketentuan larangan alih fungsi lahan yang jelas didalam awig-awig Subak Semat, begitu pula dengan sanksi yang harus diberikan kepada pelaku alih fungsi lahan. Tidak terdapat batasan yang jelas bagi anggota subak jika mereka ingin menjual lahannya, sehingga menyebabkan anggota dapat dengan bebas mengalih fungsikan lahan yang mereka punya. Tidak adanya aturan dan ketentuan yang jelas menyebabkan alih fungsi lahan yang terjadi pada Subak Semat tidak dapat dikendalikan. Perlunya larangan alih fungsi lahan di dalam awig-awig Subak Semat dirasa perlu oleh responden penelitian. Responden menyatakan bahwa dengan adanya ketentuan yang jelas mengenai larangan alih fungsi lahan menyebabkan adanya batasan yang jelas bagi anggota jika ingin menjual lahannya, begitu pula dengan sanksi yang ditetapkan untuk pelaku alih fungsi lahan perlu diatur dengan baik, sehingga terdapat tanggung jawab yang jelas bagi pelaku alih fungsi lahan.

Pelaksanaan sangkep untuk membentuk ketentuan larangan alih fungsi lahan juga tidak pernah dilaksanakan pada Subak Semat, padahal hal tersebut dirasakan perlu oleh responden. Adanya pembahasan mengenai pembentukan larangan alih fungsi lahan dalam awig-awig akan menjadi media para responden untuk menyampaikan keinginan mereka terhadap batasan yang jelas untuk menjual lahan, sehingga tidak terdapat kebingungan dalam aturan menjual lahan. Pelaku alih fungsi 
lahan, tidak perlu melaporkan keinginan mereka untuk mengalih fungsikan lahannya kepada pengurus subak, sehingga pengurus subak tidak mendapatkan informasi dari pelaku alih fungsi lahan. Masalah yang akan timbul adalah kurang lengkapnya data administratif yang dimiliki oleh subak, sehingga laporan tersebut juga dianggap penting oleh responden. Indikator regulasi pengendalian alih fungsi lahan disajikan pada Tabel 2.

Tabel 2.

Perlunya Larangan Alih Fungsi Lahan pada Awig-awig Subak Semat, Tahun 2016

\begin{tabular}{cccc}
\hline & Parameter & $\begin{array}{c}\text { Pencapaian } \\
\text { Skor }\end{array}$ & Kategori \\
\hline R1 & $\begin{array}{c}\text { Awig-awig mengatur larangan alih } \\
\text { fungsi lahan }\end{array}$ & 80,5 & Perlu \\
R2 & $\begin{array}{c}\text { Awig-awig menetapkan sanksi bagi } \\
\text { pelaku alih fungsi lahan }\end{array}$ & 80,5 & Perlu \\
R3 & $\begin{array}{c}\text { Pelaksanaan sangkep pembuatan } \\
\text { awig-awig alih fungsi lahan } \\
\text { R4 }\end{array}$ & 81,7 & Perlu \\
& $\begin{array}{c}\text { Adanya laporan jika ingin melakukan } \\
\text { alih fungsi lahan }\end{array}$ & 81,7 & Perlu \\
\hline & Indikator Regulasi/awig-awig & 81,17 & Perlu \\
\hline
\end{tabular}

\subsubsection{Aktivitas Subak}

Aktivitas yang terdapat di dalam Subak Semat berada pada kategori baik. Terdapat delapan parameter yang digunakan untuk menentukan aktvitas subak pada Subak Semat, meliputi perubahan aktivitas akibat alih fungsi lahan, pengaruh perubahan terhadap anggota subak, pengaruh alih fungsi lahan terhadap aktivitas keagamaan kolektif, pengaruh alih fungsi lahan terhadap aktivitas keagamaan individual, koordinasi antarpengurus subak, koordinasi antara pengurus dengan anggota, koordinasi antaranggota, dan jumlah anggota yang kehilangan status anggota.

Terdapat tiga parameter yang termasuk pada kategori sedang, yaitu pengaruh perubahan terhadap anggota subak, pengaruh alih fungsi lahan terhadap aktivitas keagamaan kolektif, dan pengaruh alih fungsi lahan terhadap aktivitas keagamaan individual. Berdasarkan hasil penelitian diketahui bahwa mayoritas anggota subak merasakan beberapa dampak alih fungsi lahan terhadap aktivitas yang terjadi di subak, sehingga aktivitas subak mengalami beberapa perubahan. Salah satu perubahan yang paling dirasakan oleh mayoritas responden adalah berkurangnya tenaga yang ada dalam melaksanakan kegiatan, seperti gotong royong. Namun, menurut penuturan informan kunci, kendala tersebut masih dapat teratasi. Subak Semat rutin mendapatkan subsidi berupa materi dari pemerintah.

Pada parameter yang terkait mengenai koordinasi yang terjadi antara pengurus dengan pengurus dan juga pengurus dengan anggota berada pada kategori yang baik. Berdasarkan data yang didapatkan, responden menyatakan bahwa pengurus Subak Semat merupakan orang-orang yang memang berkompeten 
dibidangnya. Seluruh pengurus subak memiliki jiwa kepemimpinan yang baik, sehingga seluruh aktivitas dan juga kegiatan dalam subak dapat di manajemen dengan baik, tidak pernah terjadi kesalahan yang fatal.

Pada kasus Subak Semat ini, pada parameter yang terkait jumlah anggota yang kehilangan status keanggotaannya akibat alih fungsi lahan masih berada dalam kategori baik. Menurut data yang didapatkan, rata-rata jumlah anggota yang kehilangan status keanggotaannya sebanyak lebih dari 10 orang. Indikator aktivitas subak disajikan pada Tabel 3.

Tabel 3.

Aktivitas Subak Semat, Tahun 2016

\begin{tabular}{|c|c|c|c|}
\hline & Parameter & $\begin{array}{l}\text { Pencapaian } \\
\text { Skor }\end{array}$ & Kategori \\
\hline A1 & Perubahan aktivitas akibat alih fungsi lahan & 73,8 & Baik \\
\hline $\mathrm{A} 2$ & Pengaruh perubahan terhadap anggota subak & 62,3 & Sedang \\
\hline A3 & $\begin{array}{l}\text { Pengaruh alih fungsi lahan terhadap aktivitas } \\
\text { keagamaan kolektif }\end{array}$ & 61,1 & Sedang \\
\hline A4 & $\begin{array}{l}\text { Pengaruh alih fungsi lahan terhadap aktivitas } \\
\text { keagamaan individual }\end{array}$ & 60,0 & Sedang \\
\hline A5 & Koordinasi antarpengurus subak & 77,3 & Baik \\
\hline A6 & Koordinasi antara pengurus dengan anggota & 73,8 & Baik \\
\hline A7 & Koordinasi antaranggota & 77,0 & Baik \\
\hline A8 & Jumlah anggota yang kehilangan status anggota & 74,7 & Baik \\
\hline & Indikator Aktivitas Subak & 70,00 & Baik \\
\hline
\end{tabular}

\subsubsection{Pelayanan dan Fasilitasi Subak}

Pelayanan yang dimaksudkan disini adalah segala sesuatu kemudahan yang diberikan kepada anggota subak oleh organisasi subak, seperti bantuan-bantuan berupa subsidi yang diberikan oleh subak dan juga pembebasan pajak bagi pemilik lahan persawahan. Pelayanan yang baik akan memberikan pengaruh terhadap sikap anggota subak jika ingin menjual lahannya. Adanya pelayanan dan fasilitasi yang baik akan membuat anggota subak merasa senang untuk melaksanakan kegiatan bertani.

Keberadaan fasilitas pada suatu subak juga merupakan suatu keharusan. Fasilitas yang lengkap akan memudahkan anggota subak untuk dapat melaksanakan kegiatannya. Seluruh fasilitas yang ada tentu saja dibuat untuk membantu atau menyokong kegiatan dari organisasi subak, sehingga indikator atau aspek pelayanan dan fasilitasi memberikan pengaruh bagi kelembagaan subak untuk dapat mengendalikan alih fungsi lahan yang terjadi.

Terdapat 15 parameter yang digunakan untuk menentukan pelayanan dan fasilitasi subak pada Subak Semat, meliputi kelengkapan fasilitas subak, pengoperasian fasilitas subak, keadaan balai subak, pungutan iuran pemeliharaan fasilitas fisik jaringan irigasi, pungutan iuran pemeliharaan jaringan fisik non irigasi, 
jalan usahatani, pengetahuan jalur usahatani oleh anggota subak, penggunaan jalur usahatani oleh anggota subak, pembinaan oleh instansi, banyaknya pelaksanaan pembinaan, respon terhadap pelaksanaan pembinaan, pemberian penyuluhan informasi inovasi, subsidi PBB, subsidi UPS, dan manfaat adanya subsidi.

Terdapat empat parameter yang tergolong pada kategori sangat baik, yaitu pungutan iuran pemeliharaan fasilitas fisik jaringan irigasi, pungutan iuran pemeliharaan fasilitas fisik jaringan non irigasi, banyaknya pelaksanaan pembinaan dan manfaat adanya subsidi. Keadaan kas terkait iuran yang terdapat pada Subak Semat tergolong pada kategori yang sangat baik. Hal tersebut juga dibantu dengan adanya subsidi berupa materi yang diberikan oleh pemerintah, sehingga Subak Semat tidak pernah kekurangan biaya untuk melaksanakan pemeliharaan fasilitas subak. Subsidi berupa dana bantuan yang diberikan oleh pemerintah kepada Subak Semat rutin diberikan setiap tahunnya.

Menurut penuturan pekaseh Sebak Semat, jumlah dana bantuan yang diberikan oleh pemerintah setiap tahunnya itu mencapai 40-50 juta rupiah. Dana tersebut yang nantinya digunakan oleh Subak Semat jika ingin melaksanakan berbagai aktivitas yang memerlukan dana kolektif atau bersama, seperti gotong royong dan ritual agama kolektif. Indikator pelayanan dan fasilitasi disajikan pada Tabel 4.

Tabel 4.

Pelayanan dan Fasilitasi Subak Semat, Tahun 2016

\begin{tabular}{cccc}
\hline & Parameter & $\begin{array}{c}\text { Pencapaian } \\
\text { Skor }\end{array}$ & Kategori \\
\hline F1 & Kelengkapan fasilitas subak & 78,8 & Baik \\
F2 & Pengoperasian fasilitas subak & 82,9 & Baik \\
F3 & Keadaan balai subak & 83,5 & Baik \\
F4 & Pungutan iuran pemeliharaan fasilitas fisik & 85,7 & Sangat Baik \\
& jaringan irigasi & \\
F5 & Pungutan iuran pemeliharaan fasilitas fisik & 84,4 & Sangat Baik \\
& jaringan non irigasi & Baik \\
F6 & Jalan usahatani & 71,9 & Baik \\
F7 & Pengetahuan jalur usahatani oleh anggota & 72,3 & \\
& subak & & Baik \\
F8 & Penggunaan jalur usahatani oleh anggota & 79,0 & Baik \\
& subak & 75,5 & Sangat Baik \\
F9 & Pembinaan oleh instansi & 85,5 & Baik \\
F10 & Banyaknya pelaksanaan pembinaan & 80,5 & Baik \\
F11 & Respon terhadap pelaksanaan pembinaan & 79,4 & Baik \\
F12 & Pemberian penyuluhan informasi innovasi & Baik \\
F13 & Subsidi PBB & 78,2 & Baik \\
F14 & Subsidi UPS & 90,7 & Sangat Baik \\
F15 & Manfaat adanya subsidi & 80,00 & Baik \\
\hline
\end{tabular}




\section{Simpulan dan Saran}

\subsection{Simpulan}

Berdasarkan hasil penelitian tersebut, dapat disimpulkan bahwa peran aspek kelembagaan regulasi masih belum dapat mengendalikan adanya alih fungsi lahan pada Subak Semat, karena tidak terdapat ketentuan larangan alih fungsi lahan yang jelas dalam awig-awig Subak Semat, sehingga alih fungsi lahan yang terjadi pada Subak Semat tidak dapat dikendalikan. Peran aspek aktivitas, pelayanan, dan fasilitasi telah berada pada kategori yang baik.

\subsection{Saran}

Perlunya pembentukan awig-awig larangan alih fungsi lahan merupakan salah satu poin terpenting yang harus diperhatikan oleh kelembagaan subak. Hal tersebut perlu diperhatikan oleh kelembagaan subak tentunya untuk menjaga keberlangsungan subak. Tidak adanya pengaturan mengenai larangan alih fungsi lahan berakibat pada mudahnya anggota subak untuk mengalih fungsikan lahan yang mereka miliki.

\section{Ucapan Terima Kasih}

Terimakasih kepada seluruh pihak yang telah memberikan pengarahan, bmbingan dan juga dukungan dalam penyelesaian penelitian dan penulisan ejurnalini. Semoga penelitian ini dapat bermanfaat sebagaimana mestinya.

\section{Daftar Pustaka}

Arikunto, Suharsini. 2002. Prosedur Penelitian Suatu Pendekatan Praktik. Rineka Cipta: Jakarta

BPP. 2014. Balai Pelatihan Pertanian.Kecamatan Kuta Utara

Iqbal, M dan Sumaryanto, 2007. Strategi Pengendalian Alih Fungsi Lahan Pertanian Bertumpu Pada Partisipasi Masyarakat. Pusat Analisis Sosial Ekonomi dan Kebijakan Pertanian.Volume 5 No. 2, Juni 2007 : 167-182. Bogor

Kuncoro. 2013. BAB III Metode Penelitian. [Online] http://repository.unhas.ac.id./bitstream/handle/123456789/1717/BAB\%20III. docx? sequence $=4$.

Moleong , 2005. Metodologi Kualitatif Edisi Revisi. Bandung: PT Remaja Rosdakarya

Norman T. Uphoff., 1986. Local Institutional Development; An Alatical Sourcebook. West Hartford. Kumarian Press

Pitana, I Gde; Putra, I Gede Setiawan Adi. 2005. Revitalisasi Subak dalam Memasuki Era Globalisasi. Andi Yogyakarta

Sukmadinata, Nana Syaodih. 2013. Metode Penelitian Pendidikan. Bandung: PT Remaja Rosdakarya

Sutawan, Nyoman. 2008. Organisasi dan Manajemen Subak di Bali. Pustaka Bali Post. Denpasar

Windia, Wayan; Sudarta, Wayan; Astiti, Wayan Sri. 2015. Sistem Subak di Bali (Kajian Sosiologis). Udayana University Press. Denpasar. 